\title{
Intimate Partner Violence in Treatment Seeking Problem Gamblers
}

\author{
Amanda Roberts $^{1}$ (D) Stephen Sharman ${ }^{2} \cdot$ Jason Landon $^{3} \cdot$ Sean Cowlishaw ${ }^{4,5} \cdot$ Raegan Murphy $^{6}$. \\ Stephanie Meleck ${ }^{7} \cdot$ Henrietta Bowden-Jones ${ }^{7,8}$
}

Published online: 26 February 2019

(C) The Author(s) 2019

\begin{abstract}
The co-occurrence of Intimate Partner Violence (IPV) and gambling disorder is an emerging area of research but no studies, as yet, have examined these within a gambling treatment-seeking population from the UK. In a sample of 204 patients, the study utilised routine clinical data and the Jellinek-Inventory for assessing Partner Violence (J-IPV) to determine the prevalence of IPV perpetration and victimisation. $20.1 \%$ of participants reported any IPV in the past year; $12.3 \%$ reported perpetration and $14.1 \%$ reported victimisation in the past year. Clinical scores were greater among patients disclosing IPV; higher anxiety and depression scores coupled with victimisation, alongside greater problem gambling severity; age, anxiety, depression and debt scores among those reporting IPV perpetration. There is need for enhanced vigilance and first-line responses to IPV in problem gambling treatment services. There is also a need for professional support for the clinicians working with these clients.
\end{abstract}

Keywords Gambling $\cdot$ Disordered gambling $\cdot$ Interpersonal violence $\cdot$ Mental health $\cdot$ Treatment

\section{Introduction}

Significant numbers of gamblers encounter related problems across personal, family and vocational domains, with approximately $7.3 \%$ of adults in Great Britain reporting at least some problematic behaviours or harms annually, with a $0.7 \%$ categorised as problem gamblers (Wardle et al. 2011). Gambling was re-classified as a behavioural addiction in the most recent version of the Diagnostic Manual of Mental Disorders (American Psychiatric Association 2013), and renamed "gambling disorder" in acknowledgement of similarities across behavioural and substance addictions (Grant et al. 2010).

Many harms experienced by disordered gamblers are interpersonal, and there is mounting evidence that some

Amanda Roberts

aroberts@lincoln.ac.uk

1 School of Psychology, College of Social Science, University of Lincoln, Brayford Pool, Lincoln, Lincolnshire LN6 7TS, UK

2 School of Psychology, University of East London, Stratford, London E15 4LZ, UK

3 Department of Psychology, Gambling and Addictions Research Centre Faculty of Health \& Environmental Sciences, AUT University, 90 Akoranga Drive, Northcote, Auckland 1142, New Zealand individuals with gambling problems experience substantial difficulties in relationships (Cowlishaw et al. 2016; Dowling et al. 2009; Hodgins et al. 2007). These include occurrences of intimate partner violence (IPV) (e.g. Dowling et al. 2018; Korman et al. 2008; Roberts et al. 2016, 2018; Suomi et al. 2013, 2018), which can refer to physical or sexual violence, stalking and psychological aggression (including coercive tactics) by a current or former intimate partner (Breiding et al. 2015). A systematic review by Dowling et al. (2016) identified limited research that had examined the co-occurrence of problem gambling and IPV; however, the best available estimates from studies of community and clinical samples of problem gamblers suggested around $37 \%$ that reported physical IPV perpetration, and $38 \%$ that reported IPV victimisation. Although such figures are based on small

4 Centre for Posttraumatic Mental Health, Department of Psychiatry, University of Melbourne, Alan Gilbert Building, 161 Barry Street, Carlton, VIC 3053, Australia

5 Bristol Medical School, University of Bristol, Whatley Road, Bristol BS8 2PS, UK

6 School of Applied Psychology, UCC Enterprise Centre, University College Cork, North Mall, Cork, Ireland

7 National Problem Gambling Clinic, 69 Warwick Rd, Fulham, London SW5 9BH, UK

8 Department of Medicine, Imperial College London, South Kensington Campus, London SW7 2AZ, UK 
numbers of studies (three and four studies provided data on IPV perpetration and victimisation, respectively), these rates are substantially higher than those reported in the general population; for example, it was shown that in the UK, $7.5 \%$ of women and $4.5 \%$ of men experienced any type of domestic abuse (IPV) in 2017 (Office for National Statistics 2018).

Despite evidence of common co-occurrence involving problem gambling and IPV, there are no relevant studies of individuals attending problem gambling treatment services in the UK that have been reported. Relevant international studies of gambling problems and IPV have used non-gambling specific cohorts such as general population samples (Afifi et al. 2010; Bland et al. 1993; Liao 2008; Roberts et al. 2016, 2018), IPV perpetrators (e.g. Brasfield et al. 2012; Rothman et al. 2006), emergency room visitors (Muelleman et al. 2002) and perinatal samples (Schluter et al. 2007). In contrast, we know of only five international studies which have examined IPV in clinical contexts and have relevance to the design of problem gambling treatment services; these have all been conducted outside the UK and in countries including Australia (Dowling et al. 2014; Raylu and Oei 2009), Spain (Echeburua et al. 2011); USA (Lorenz and Shuttlesworth 1983); Canada (Korman et al. 2008); and New Zealand (Palmer du Preez et al. 2018). Moreover, only two of these studies have considered links with a limited range of clinical indices that may signal increased risk of IPV, and thus inform the design of identification strategies and targeted interventions for IPV in gambling treatment services. By way of illustration, using problem gambling samples, there is one study that considered the role of alcohol use (Korman et al. 2008), and another study that examined anxiety and depression (Echeburua et al. 2011).

The broad aim of this study was to report on the rate of occurrence and risk factors for IPV in a sample of men and women seeking treatment for gambling problems in a UK national context. More specifically, the study aimed to:

1) Examine the prevalence of IPV perpetration and victimisation, respectively, among both males and females seeking treatment for gambling disorder in the UK; and

2) Evaluate whether patients reporting IPV could be distinguished from those that did not in terms of clinical characteristics to signpost those who may be of heightened risk of IPV.

\section{Method}

\section{Sample}

The study was based on routine data collected from individuals seeking treatment at the National Problem Gambling
Clinic (NPGC), part of the Central North-West London National Health Service (NHS) Trust, UK from March 2014 until October 2014 ( 8 months). The clinic is the first and only NHS multidisciplinary treatment centre in the UK for the treatment of problem gamblers. The sample of $n=204$ patients comprised 185 men (90.7\%) and 19 women (9.3\%), with an average age of $35.6(\mathrm{SD}=10.9)$. The only inclusion criterion was that patients were classified as problem gamblers (scoring $8+$ on the PGSI- see below). Demographic characteristics are shown in Table 1.

\section{Measures}

Problem/pathological gambling Problem Gambling Severity Index (PGSI): The PGSI is a 9-item self-report tool that measures gambling problem severity (Ferris and Wynne 2001). The scale assesses problematic gambling behaviours and interrelated adverse consequences and harms. Items are scored from 0 to $3(0=$ never, $1=$ sometimes, $2=$ most of the time, $3=$ almost always). PGSI scores range from 0 to 27 and yields recognised interpretive categories: a score of 0 indicates a non-problem gambler; 1-2 'low- risk'; 3-7 'moderate risk', 8 and above 'problem gambler' (Ferris and Wynne 2001). The scale has good internal reliability (Cronbach's $\alpha=0.84$ ) (Ferris and Wynne 2001), and more recent studies have reported excellent internal consistency (Cronbach's $\alpha=.90$ ) (Williams and Volberg 2014).

Intimate Partner Violence Jellinek-Inventory for assessing Partner Violence (JIPV): The J-IPV comprises 4-items that identify perpetrators and victims of verbal and physical IPV in the past year (Kraanen et al. 2013). Questions are asked "Has it occurred in the past year that the situation with your partner got so out of hand that your partner has threatened you, or that he/she threatened to harm you?" and "Has it occurred in the past year that the situation with your partner got so out of hand and that your partner has been physically abusive towards you and for instance hit or kicked you?" Participants were coded as victims when at least one of these two questions were answered positively [IPV victimization]. Participants were coded as perpetrators when at least one of the following two questions were answered positively [IPV perpetration]. "Conversely, has it occurred in the past year that the situation with your partner got so out of hand that you acted in a threatening way to your partner, or threatened to hurt him/her?" and "And has it occurred in the past year that the situation with your partner got so out of hand that you became physically violent and, for example, slapped, hit or kicked your partner?" Any IPV was coded when at least one of the four questions were answered positively. Across two independent studies, the scale has been found to have good psychometric properties within a 
Table 1 Demographic characteristics of the sample

\begin{tabular}{|c|c|c|c|c|c|c|c|c|c|c|}
\hline & \multicolumn{2}{|c|}{$\begin{array}{l}\text { All } \\
\text { respondents* }\end{array}$} & \multicolumn{2}{|c|}{$\begin{array}{l}\text { Non-IPV } \\
\text { exposed }\end{array}$} & \multicolumn{2}{|c|}{$\begin{array}{l}\text { IPV } \\
\text { victim }\end{array}$} & \multicolumn{2}{|c|}{$\begin{array}{l}\text { IPV } \\
\text { perpetrator }\end{array}$} & \multicolumn{2}{|c|}{ Any IPV } \\
\hline & $\mathrm{N}$ & $(\%)$ & $\mathrm{N}$ & $(\%)$ & $\mathrm{N}$ & $(\%)$ & $\mathrm{N}$ & $(\%)$ & $\mathrm{N}$ & $(\%)$ \\
\hline \multicolumn{11}{|l|}{ Gender } \\
\hline Male & 187 & 90.3 & 150 & 81.1 & 27 & 14.4 & 20 & 10.7 & 35 & 18.7 \\
\hline Female & 19 & 9.7 & 13 & 68.4 & 2 & 10.5 & 5 & 26.3 & 6 & 31.6 \\
\hline \multicolumn{11}{|l|}{ Age group } \\
\hline Age 16-24 & 23 & 11.1 & 21 & 91.3 & 1 & 4.3 & 1 & 4.3 & 2 & 8.7 \\
\hline Age $25-34$ & 91 & 44.4 & 76 & 83.5 & 11 & 12.1 & 9 & 9.9 & 15 & 16.5 \\
\hline Age $35-44$ & 46 & 23.2 & 31 & 67.4 & 10 & 21.7 & 7 & 15.2 & 15 & 32.6 \\
\hline Age $45-54$ & 30 & 14.5 & 25 & 83.3 & 4 & 13.3 & 4 & 13.3 & 5 & 16.7 \\
\hline Age $55+$ & 14 & 6.8 & 10 & 71.4 & 3 & 21.4 & 4 & 28.6 & 4 & 28.6 \\
\hline \multicolumn{11}{|l|}{ Marital status } \\
\hline Single & 91 & 44 & 77 & 84.6 & 10 & 11.0 & 8 & 8.8 & 14 & 15.4 \\
\hline Married & 50 & 24.2 & 40 & 81.6 & 7 & 14.0 & 6 & 12.0 & 9 & 18.4 \\
\hline Separated/ divorced/ widowed & 15 & 7.2 & 10 & 66.7 & 2 & 13.3 & 3 & 20.0 & 5 & 33.3 \\
\hline Couple & 31 & 15 & 23 & 76.7 & 6 & 19.4 & 4 & 12.9 & 7 & 23.3 \\
\hline \multicolumn{11}{|l|}{ Employment } \\
\hline Employed & 147 & 71 & 121 & 83.4 & 21 & 14.3 & 13 & 8.8 & 24 & 16.6 \\
\hline Unemployed & 32 & 15.9 & 24 & 75 & 4 & 12.5 & 5 & 15.6 & 8 & 25.0 \\
\hline Retired & 3 & 1.4 & 2 & 66.7 & 1 & 33.3 & 1 & 33.3 & 1 & 33.3 \\
\hline Other & 17 & 8.2 & 11 & 64.7 & 2 & 11.8 & 5 & 29.4 & 6 & 35.3 \\
\hline \multicolumn{11}{|l|}{ Education } \\
\hline Degree Level or above & 76 & 36.7 & 61 & 80.3 & 12 & 15.8 & 9 & 11.8 & 15 & 19.7 \\
\hline 'A-Level' or equivalent & 34 & 16.4 & 26 & 78.7 & 6 & 17.6 & 3 & 8.8 & 7 & 21.2 \\
\hline 'GCSE' or other & 55 & 27.1 & 45 & 81.8 & 7 & 12.7 & 6 & 10.9 & 10 & 18.2 \\
\hline None & 18 & 8.7 & 12 & 66.7 & 2 & 11.1 & 5 & 27.8 & 6 & 33.3 \\
\hline
\end{tabular}

substance abusing population for determining any IPV perpetration; sensitivity (.80 and .84), PPV (Positive Predictive Value) (.75 and .74) and NPV (Negative Predictive Value) (.85 and .89) and any IPV victimisation; sensitivity (.83 and .80), PPV (.80 and .74) and NPV (.87 and .86) (Kraanen et al. 2013).

Depression Patient Health Questionnaire (PHQ 9): The PHQ9 is a 9-item instrument which scores each of the 9 DMS-IV criteria for depression (Kroenke et al. 2001). Items are scored from 0 to $3(0=$ not at all; $1=$ several days; $2=$ more than half the days; 3 = nearly every day). Scores range from 0 to 27 and reflect no depression (0-4), mild (5-9), moderate (10-14), moderately severe (15-19) and severe (20-27) depression. It has been commended for its high sensitivity and specificity for assessing severity of depression across diverse populations (Kroenke et al. 2001).

Anxiety Disorder Generalised Anxiety Disorder - 7 item scale (GAD-7): The GAD-7 is a 7-item measure that has good sensitivity and specificity for Generalised Anxiety Disorder (Spitzer et al. 2006). Items are scored from 0 to $3(0=$ not at all $1,=$ several days; $2=$ more than half the days; $3=$ nearly every day), with aggregate scores ranging from 0 to 21 . Scores of 5,10 , and 15 provide cut off criteria for mild, moderate, and severe anxiety (Spitzer et al. 2006).

Alcohol Use Alcohol Use Disorders Identification TestConsumption Questions (AUDIT-C): The 3-item AUDIT-C consists of the first three items from the World Health Organization's 10-item AUDIT, which asks about alcohol consumption (Babor et al. 2001). The first two questions assess regular drinking measured by frequency and quantity. The third assesses binge drinking, defined by six or more alcoholic drinks in one sitting, at least once a month in the preceding 3 months. Answers are scored from 0 to 4 and the final score is the sum of the responses. A score of $5+$ indicates hazardous drinking (Bush et al. 1998). The AUDIT-C is a validated and well-established screening tool for unhealthy alcohol use (Dawson et al. 2005).

Monetary debts and losses Participants were asked questions about their estimated total debts through gambling using an open response format. 
Sociodemographic Measures Data collected (categorisation in parentheses) included; Gender (male, female); Age (16-24, 25-34, 35-44, 45-54, 55+); marital status (single, married, couple separated/ divorced/ widowed); employment status (employed, unemployed, retired, other); qualifications (degree/ professional, 'A-Level' (Advanced Level) or equivalent, 'GCSE' (General Certificate of Secondary Education) or other, none). Please note that we used age groups for the descriptive data in Table 1 to maintain consistency with previous publications (see Roberts et al. 2016). However, age was treated as a continuous variable in the substantive analyses.

\section{Procedure}

Data were collected between March 2014 and October 2014 from clients who were voluntarily seeking treatment at the NPGC. All clients entering the service during the study period completed a questionnaire prior to meeting with a clinician for their first appointment. This included the J-IPV, the PGSI and clinical scales (PHQ-9, GAD-7, AUDIT-C). Demographic details were collected from a referral form completed by the clients prior to assessment. During the study period there were $100 \%$ clients (204 participants) who consented to the use of their data. All participants were subsequently classified as problem gamblers (scoring 8 or more on the PGSI). All data was collected in accordance with NHS regulations of standard clinical practice.

\section{Data Analysis}

The data were analysed using the Statistical Package for the Social Sciences (SPSS) 22.0. Analyses first describes demographic and intake information for clients who had reported IPV versus those who had not (see Table 1). Please note that not all categories total $100 \%$ because of missing data. To contextualise our sample statistics and support inferences to population parameters, we calculated the binomial parameters using the $Z \alpha / 2$ interval using a 95\% confidence interval (for a 95\% confidence, the alpha value is $5 \%$ or 0.05 and the multiplier is a $\mathrm{z}$-value with $\alpha / 2$, or 0.025 and this corresponds to a $\mathrm{z}$ value of 1.96 using the standard normal table.) We report the CI below in parentheses after sample percentages. Binary logistic regression was then used to examine relationships and estimate differences in gambling, alcohol use, anxiety, health, age, debts and losses according to experience of IPV. For all analyses those with an experience of IPV provided the reference category. A significance level of 5\% was adopted for all analyses.

\section{Results}

During the study period, there were 41 clients (20.1\%) reporting any IPV (as a perpetrator or victim) in the past year
(95\% CI $=14.64 \%-25.35 \%)$ (Males: $n=35,18.7 \%, 95 \%$ $\mathrm{CI}=13.2 \%-24.5 \%$; Females: $n=6,31.6 \%, 95 \% \mathrm{CI}=$ $10.6 \%-52.38 \%)$. Past year perpetration was reported by 25 clients $(12.3 \%, 95 \mathrm{CI}=7.75 \%-16.74 \%$ ) (Males: $n=20$, $10.7 \%, 95 \% \mathrm{CI}=6.37 \%-15.36 \%$; Females: $n=5,26.3 \%$, $95 \% \mathrm{CI}=6.5 \%-46.09 \%)$. Past year victimisation was reported by 29 clients $(14.1 \%, 95 \% \mathrm{CI}=9.4 \%-18.99 \%)$ (Males: $n=27,14.4 \%, 95 \% \mathrm{CI}=13.93 \%-19.47 \%$; Females $n=2$, $10.5 \%, 95 \% \mathrm{CI}=0 \%-24 \%)$.

A series of binary logistic regression models were estimated to examine associations with a series of exogenous predictors (gambling, alcohol use, anxiety, health, age, debts and losses) and IPV victimisation (Table 2) and perpetration (Table 3). Results showed that relative to non-victims, the victims of IPV were likely to score higher on PGSI (OR = $1.13, p<0.01)$, the PHQ-9 (OR $=1.06, p<0.05)$ and the GAD-7 (OR $=1.07, p<0.05)$. Perpetrators of IPV (relative to non-perpetrators) were likely to be older $(\mathrm{OR}=1.04$, $p<0.01)$, score higher on PHQ-9 (OR $=1.06, p<0.05)$ and the GAD-7 ( $\mathrm{OR}=1.09, p<0.05)$. There were no significant associations with either IPV victimisation or perpetration and alcohol risk, current debts or total losses.

\section{Discussion}

These findings contribute to the small body of international evidence which indicates the importance of considering IPV in the context of specialist treatment for problem gambling. To our knowledge, this is the first study to investigate IPV in a problem gambling treatment-seeking population in the UK. Results indicate that overall, around $20.1 \%$ of clients reported any IPV, which included $12.3 \%$ reporting past year perpetration and $14.1 \%$ reporting victimisation. These figures are substantially higher than estimates from the Crime Survey for England and Wales (CSEW), for example, which suggests $7.5 \%$ of women and $4.5 \%$ of men that experienced any type of domestic abuse (IPV) in 2017 (Office for National Statistics 2018). The measurement of IPV is more comprehensive in the CSEW, and includes controlling, coercive, threatening behaviour, violence or abuse between intimate partners or family members regardless of gender or sexuality. This encompasses not only physical violence, but also psychological, sexual, financial, and emotional abuse (Office for National Statistics 2018). Given that one fifth of patients in gambling treatment services are willing to disclose a much narrower definition of IPV which excludes sexual and many non-physical forms of IPV (the four questions from the J-IPV covered threats and physical violence only), these findings suggest a major and largely hidden clinical and health-related issue for these services.

The findings are consistent with the small number of international studies in gambling treatment populations which 
Table 2 Independent associations between IPV victimisation and clinical correlates

\begin{tabular}{|c|c|c|c|}
\hline Variable (n) & No IPV Victimisation $\bar{x}$ (Median) & IPV Victimisation $\bar{x}$ (Median) & $\mathrm{OR}(\mathrm{CI})$ \\
\hline Age (206) & $34.95(33)$ & $38.75(36)$ & $1.03(0.99-1.06)$ \\
\hline PGSI (200) & $19.05(20)$ & $21.86(22)$ & $1.13(1.03-1.24) * *$ \\
\hline PHQ-9 (199) & $11.76(12)$ & $15.24(15)$ & $1.06(1.00-1.11) *$ \\
\hline GAD-7 (199) & $9.95(10)$ & $12.86(13)$ & $1.07(1.00-1.14) *$ \\
\hline AUDIT-C (188) & $4.74(5)$ & $4.74(6)$ & $1.00(0.85-1.17)$ \\
\hline Total debts (200) & $16,183(5000)$ & $95,256(10000)$ & $1.00(1.00-1.00)$ \\
\hline
\end{tabular}

$* P \leq 0.05 ; * * P \leq 0.01$

Bold is where the associations are significant

have used similar brief IPV screening measures. For example, Dowling et al. (2014) reported that 22.9\%-27.0\% of their gambling treatment sample from Australia disclosed IPV according to the Hurt-Insulted-Threaten-Screamed (HITS); Sherin et al. 1998). In contrast, the findings are lower than those from studies involving more comprehensive IPV assessments (for example, Korman et al. (2008) found that $56 \%$ and $60 \%$ of 248 problem gamblers reported IPV perpetration and victimisation, respectively, when using the Conflict Tactics Scale; CTS). Such findings may suggest that brief screens provide underestimates of IPV in gambling treatment services, including the context and implications of IPV, and particular non-physical abuse behaviours that reflect coercive control. The primary implication is that the current figures should be treated as lower bound estimates of IPV in gambling treatment services, and that the extent of the problem is likely to be far greater than implied by these results. Future research could consider the use of the more comprehensive CTS which is a valid and reliable measure of family violence (Straus and Douglas 2004).

Findings from the current study suggest that patients who reported IPV could be distinguished from those did not in terms of clinical characteristics that are commonly measured in gambling treatment services. For example, participants reporting IPV victimisation or perpetration also indicted significantly higher clinical depression and anxiety scores obtained using routine tools. Such results are consistent with studies that have shown that IPV predicts poor mental health outcomes including depression and anxiety (Afifi et al. 2010; Coker et al. 2002) and gambling severity (Roberts et al. 2016). They imply relatively severe and complex mental health problems among clients who experience IPV, and may also suggest vulnerable groups that could inform the design of selective screening strategies in the future. Likewise, participants who reported IPV victimisation in the past year had significantly higher PGSI scores compared to those who did not. It has been suggested that IPV victimisation may be causally related to disordered gambling whereby victims of IPV may use gambling as a coping mechanism or to physical and emotionally escape (e.g. Afifi et al. 2010; Echeburua et al. 2011; Korman et al. 2008). Given that treatment seekers are a small and selective proportion of all people with gambling problems, further evidence from nonclinical samples is needed to determine the nature of the relationships involving problem gambling and IPV victimisation and perpetration. Our data showcase associations and thus we cannot make any claim to the direction of causality.

The findings highlight the need for service-level responses to IPV in treatment services for gambling problems in the UK. There is a sizable body of literature on the identification and responses to IPV in other health service environments (García-Moreno et al. 2015), which can help inform the design of initiatives in gambling treatment. This literature has focussed mainly on IPV victimisation, rather than perpetration, and highlights the range of identification strategies that may be considered, including universal or selective screening, and so-called 'case-finding' strategies (O’Doherty et al. 2014). It also indicates various clinical

Table 3 Independent associations between IPV perpetration and clinical correlates

\begin{tabular}{|c|c|c|c|}
\hline Variable (n) & No IPV perpetration $\bar{x}$ (Median) & IPV perpetration $\bar{x}$ (Median) & $\mathrm{OR}(\mathrm{CI})$ \\
\hline Age (203) & $34.67(33)$ & $40.96(39)$ & $1.04(1.01-1.08)^{* * *}$ \\
\hline PGSI (198) & $19.22(20)$ & $20.71(21)$ & $1.06(0.97-1.16)$ \\
\hline PHQ-9 (197) & $11.80(12)$ & $15.30(16)$ & $1.06(1.00-1.10)^{*}$ \\
\hline GAD-7 (197) & $9.93(10)$ & $13.57(14)$ & $1.09(1.02-1.18)^{*}$ \\
\hline AUDIT-C (186) & $4.69(5)$ & $5.20(6)$ & $1.08(0.89-1.30)$ \\
\hline Total debts (197) & $17,443(50000)$ & $96,776(11000)$ & $1.00(1.00-1.00)$ \\
\hline
\end{tabular}

$* P \leq 0.05 ; * * P \leq 0.01$

Bold is where the associations are significant 
responses that may be appropriate, to a greater or lesser extent, including supportive first-line responses with referral to specialist services (Feder et al. 2011), or direct interventions (e.g., brief counselling) aimed at improving patient safety and well-being (Hegarty et al. 2013). There is a pressing need for research to appraise the suitability of such strategies and responses to victims, including studies of the nature of IPV in gambling services, the acceptability of initiatives to service providers and users, and ultimately studies which can demonstrate benefits for patients. While there should be a priority focus on victims of IPV, the study also suggests opportunities to address IPV perpetration in gambling services, which may provide an important context for identifying men and women at various stages of change. This includes male perpetrators who may be more responsive to intervention when compared to those who typically participate in IPV perpetrator programs (for example, who are often mandated to attend by the criminal justice system) (Tarzia et al. 2017).

Although the current study allowed us to present interesting results, there were several limitations. There were differences between the male and female participants in our sample. The rate of perpetration and IPV overall was higher in females than males, and this may be consistent with findings from prior population-based research (Straus 2011). However, these findings should be interpreted cautiously in the context of controversy regarding the nature of gender symmetry or asymmetry in IPV (Dutton 2012; Johnson 2011), and given (a) the very small number of females in this sample $(n=19)$, which support imprecise estimates of prevalence, and (b) the limitations of the screening tool which does not measure the impacts of violence (which are greater for women) (Straus 2011). Moreover, data collection across a small time-frame (8 months) presents several challenges. The IPV samples were small and provided low levels of statistical precision. Other limitations include the use of the short JIPV as a self-report instrument (see above). The measure was given to participants prior to their initial assessment, and thus before a therapeutic relationship was formed. Participants may tend to deny or minimize IPV in this context using self-report (Kraanen et al. 2013). It has also been suggested that although the JIPV demonstrated good psychometric properties in substance abuse treatment centres, these findings may not generalize to other settings (Kraanen et al. 2013); the NPGC is uniquely situated within the UK National Health Service. To further understand the intricacies of IPV, more detailed scales are needed to provide information about the diverse ways in which IPV can manifest (e.g., via psychological aggression).

Despite the limitations, our findings add support to previous international literature that has shown frequent co-occurrence between IPV and problem gambling. The precise relationship remains subject to speculation; it has been suggested that the strain and tension associated with the harms of problem gambling (e.g. loss of finances and poor communication) can either exacerbate or directly lead to stress and antagonism that is directed towards others, which culminates in the perpetration of violence by partners (Afifi et al. 2010; Korman et al. 2008). Alternatively, it may be that the shared mechanisms that underlie disordered gambling (e.g., impulsivity) may also account for increased propensity to anger and ultimately IPV (Korman et al. 2008). Likewise, it has been proposed that gambling is used as a means of escape from negative environments and emotional states (e.g. Wood and Griffiths 2007) and negative relationship dynamics (e.g. IPV) can lead to greater gambling severity (Hodgins et al. 2007). It is likely that all these suppositions go some way to explaining the complex relationship between disordered gambling and IPV.

The study aimed to address a gap in the literature by using a national sample of gambling- treatment seeking individuals. Improved understanding of the relationship between gambling problems and IPV is a positive step towards informing treatment, intervention and prevention strategies. There is a need for enhanced vigilance (and possible screening) for IPV and related issues within Problem Gambling treatment services as well as first-line responses. Service should also consider the implications of underlying comorbidities, and tailor treatment for clients who exhibit IPV by offering enhanced treatment to deal with risks for safety and additional underlying psychopathology. There is also a need for professional support for the clinicians working with these clients.

Funding This research did not receive any specific grant from funding agencies in the public, commercial, or not-for-profit sectors.

\section{Compliance with Ethical Standards}

Conflicts of Interest The National Problem Gambling Clinic in London is partly funded by the NHS, and partly funded by GambleAware; a charity that receives gambling industry funds and distributes these to treatment agencies in the UK. The authors have no conflicts of interest to declare.

Data Statement The data was collected from treatment- seeking clients as a consequence, the research data is confidential.

Open Access This article is distributed under the terms of the Creative Commons Attribution 4.0 International License (http:// creativecommons.org/licenses/by/4.0/), which permits unrestricted use, distribution, and reproduction in any medium, provided you give appropriate credit to the original author(s) and the source, provide a link to the Creative Commons license, and indicate if changes were made.

Publisher's Note Springer Nature remains neutral with regard to jurisdictional claims in published maps and institutional affiliations.

\section{References}

Afifi, T. O., Brownridge, D. A., MacMillan, H., \& Sareen, J. (2010). The relationship of gambling to intimate partner violence and child maltreatment in a nationally representative sample. Journal of 
Psychiatric Research, 44(5), 331-337. https://doi.org/10.1016/j. jpsychires.2009.07.010.

American Psychiatric Association. (2013). Diagnostic and statistical manual of mental disorders (5th ed.). Arlington: American Psychiatric Publishing.

Babor, T. F., Biddle-Higgins, J. C., Saunders, J. B., \& Monteiro, M. G. (2001). AUDIT: The alcohol use disorders identification test: Guidelines for use in primary health care. Geneva: World Health Organization.

Bland, R. C., Newman, S. C., Orn, H., \& Stebelsky, G. (1993). Epidemiology of pathological gambling in Edmonton. The Canadian Journal of Psychiatry, 38(2), 108-112. https://doi.org/ 10.1177/070674379303800207.

Brasfield, H., Febres, J., Shorey, R., Strong, D., Ninnemann, A., Elmquist, J., Andersen, S. M., Bucossi, M., Schonbrun, Y. C., Temple, J. R., \& Stuart, G. L. (2012). Male batterers' alcohol use and gambling behavior. Journal of Gambling Studies, 28, 77-88. https://doi.org/10.1007/s10899-011-9246-0.

Breiding, M., Basile, K. C., Smith, S. G., Black, M. C., \& Mahendra, R. R. (2015). Intimate partner violence surveillance: uniform definitions and recommended data elements. Version 2.0. National Center for Injury Prevention and Control, Centers for Disease Control and Prevention, Atlanta (GA).

Bush, K., Kivlahan, D. R., McDonell, M. B., Fihn, S. D., \& Bradley, K. A. (1998). The AUDIT alcohol consumption questions (AUDIT-C): An effective brief screening test for problem drinking. Archives of Internal Medicine, 158(16), 1789-1795. https://doi.org/10.1001/ archinte.158.16.1789.

Coker, A. L., Davis, K. E., Arias, I., Desai, S., Sanderson, M., Brandt, H. M., \& Smith, P. H. (2002). Physical and mental health effects of intimate partner violence for men and women. American Journal of Preventive Medicine, 23(4), 260-268. https://doi.org/10.1016/ S0749-3797(02)00514-7.

Cowlishaw, S., Suomi, A., \& Rodgers, B. (2016). Implications of gambling problems for family and interpersonal adjustment: Results from the Quinte longitudinal study. Addiction, 111, 1628-1636. https://doi.org/10.1111/add.13402.

Dawson, D. A., Grant, B. F., Stinson, F. S., \& Zhou, Y. (2005). Effectiveness of the derived alcohol use disorders identification test (AUDIT-C) in screening for alcohol use disorders and risk drinking in the US general population. Alcoholism: Clinical and Experimental Research, 29, 844-854. https://doi.org/10.1097/01. ALC.0000164374.32229.A2.

Dowling, N., Smith, D., \& Thomas, T. (2009). The family functioning of female pathological gamblers. International Journal of Mental Health and Addiction, 7, 29-44. https://doi.org/10.1007/s11469007-9126-0.

Dowling, N. A., Jackson, A. C., Suomi, A., Lavis, T., Thomas, S. A., Patford, J., Harvey, P., Battersby, M., Koziol-McLain, J., Abbott, M., \& Bellringer, M. E. (2014). Problem gambling and family violence: Prevalence and patterns in treatment-seekers. Addictive Behaviors, 39, 1713-1717. https://doi.org/10.1016/j.addbeh.2014. 07.006 .

Dowling, N., Suomi, A., Jackson, A., Lavis, T., Patford, J., Cockman, S., Thomas, S., Bellringer, M., Koziol-McLain, J., Battersby, M., Harvey, P., \& Abbott, M. (2016). Problem gambling and intimate partner violence: A systematic review and meta-analysis. Trauma, Violence \& Abuse, 17(1), 43-61. https://doi.org/10.1177/ 1524838014561269.

Dowling, N. A., Ewin, C., Youssef, G. J., Merkouris, S. S., Suomi, A., Thomas, S. A., \& Jackson, A. C. (2018). Problem gambling and family violence: Findings from a population-representative study. Journal of Behavioral Addictions, 7(3), 806-813. https://doi.org/ 10.1556/2006.7.2018.74
Dutton, D. G. (2012). The case against the role of gender in intimate partner violence. Aggression and Violent Behavior, 17(1), 99-104. https://doi.org/10.1016/j.avb.2011.09.002.

Echeburua, E., Gonzalez-Ortega, I., de Corral, P., \& Polo-Lopez, R. (2011). Clinical gender differences among adult pathological gamblers seeking treatment. Journal of Gambling Studies, 27, 215-227. https://doi.org/10.1007/S10899-010-9205-1.

Feder, G., Davies, R. A., Baird, K., Dunne, D., Eldridge, S., Griffiths, C., Gregory, A., Howell, A., Johnson, M., Ramsay, J., \& Rutterford, C. (2011). Identification and referral to improve safety (IRIS) of women experiencing domestic violence with a primary care training and support programme: A cluster randomised controlled trial. The Lancet, 378(9805), 1788-1795. https://doi.org/10.1016/S01406736(11)61179-3.

Ferris, J., \& Wynne, H. (2001). The Canadian problem gambling index: Final report. Ottawa: Canadian Centre on Substance Abuse.

García-Moreno, C., Hegarty, K., d'Oliveira, A. F. L., Koziol-McLain, J., Colombini, M., \& Feder, G. (2015). The health-systems response to violence against women. The Lancet, 385(9977), 1567-1579. https://doi.org/10.1016/S0140-6736(14)61837-7.

Grant, J. E., Potenza, M. N., Weinstein, A., \& Gorelick, D. A. (2010). Introduction to behavioral addictions. The American Journal of Drug and Alcohol Abuse, 36(5), 233-241. https://doi.org/10.3109/ 00952990.2010.491884.

Hegarty, K., O'Doherty, L., Taft, A., Chondros, P., Brown, S., Valpied, J., Astbury, J., Taket, A., Gold, L., Feder, G., \& Gunn, J. (2013). Screening and counselling in the primary care setting for women who have experienced intimate partner violence (WEAVE): A cluster randomised controlled trial. The Lancet, 382(9888), 249-258. https://doi.org/10.1016/S0140-6736(13)60052-5.

Hodgins, D., Shead, N., \& Makarchuk, K. (2007). Relationship satisfaction and psychological distress among concerned significant others of pathological gamblers. Journal of Nervous and Mental Disease, 195, 65-71. https://doi.org/10.1097/01.nmd.0000252382.47434.a6.

Johnson, M. P. (2011). Gender and types of intimate partner violence: A response to an anti-feminist literature review. Aggression and Violent Behavior, 16(4), 289-296. https://doi.org/10.1016/j.avb. 2011.04.006.

Korman, L. M., Collins, J., Dutton, D., Dhayananthan, B., LittmanSharp, N., \& Skinner, W. (2008). Problem gambling and intimate partner violence. Journal of Gambling Studies, 24, 13-23. https:// doi.org/10.1007/s10899-007-9077-1.

Kraanen, F. L., Vedel, E., Scholing, A., \& Emmelkamp, P. M. (2013). Screening on perpetration and victimization of intimate partner violence (IPV): Two studies on the validity of an IPV screening instrument in patients in substance abuse treatment. PLoS One, 8(5), e63681. https://doi.org/10.1371/journal.pone.006368.

Kroenke, K., Spitzer, R. L., \& Williams, J. B. (2001). The PHQ-9: Validity of a brief depression severity measure. Journal of General Internal Medicine, 16(9), 606-613. https://doi.org/10.1046/j.15251497.2001.016009606.x.

Liao, M. S. (2008). Intimate partner violence within the Chinese community in San Francisco: Problem gambling as a risk factor. Journal of Family Violence, 23, 671-678. https://doi.org/10.1007/s10896-0089190-7.

Lorenz, V. C., \& Shuttlesworth, D. E. (1983). The impact of pathological gambling on the spouse of the gambler. Journal of Community Psychology, 11(1), 67-76. https://doi.org/10.1002/15206629(198301)11:1.

Muelleman, R. L., DenOtter, T., Wadman, M. C., Tran, T. P., \& Anderson, J. (2002). Problem gambling in the partner of the emergency department patient as a risk factor for intimate partner violence. Journal of Emergency Medicine, 23, 307-312. https://doi.org/10.1016/S07364679(02)00543-7.

O’Doherty, L. J., Taft, A., Hegarty, K., Ramsay, J., Davidson, L. L., \& Feder, G. (2014). Screening women for intimate partner violence in 
healthcare settings: Abridged Cochrane systematic review and metaanalysis. British Medical Journal, 348, g2913. https://doi.org/10. 1136/bmj.g2913.

Office for National Statistics. (2018). Crime survey for England and Wales, 2016-2017. [data collection]. UK data service. SN: 8140, https://doi.org/10.5255/UKDA-SN-8140-1.

Palmer du Preez, K., Bellringer, M., Pearson, J., Dowling, N., Suomi, A., Koziol-Mclain, J., Wilson, D., \& Jackson, A. (2018). Family violence in gambling help-seeking populations. International Gambling Studies, 1-18. https://doi.org/10.1080/14459795.2018. 1480648.

Raylu, N., \& Oei, T. S. (2009). Factors associated with the severity of gambling problems in a community gambling treatment agency. International Journal of Mental Health and Addiction, 7(1), 124137. https://doi.org/10.1007/s11469-008-9160-6.

Roberts, A., Coid, J., King, R., Murphy, R., Turner, J., Bowden-Jones, H., Du Preez, K. P., \& Landon, J. (2016). Gambling and violence in a nationally representative sample of UK men. Addiction, 111(12), 2196-2207. https://doi.org/10.1111/add.13522.

Roberts, A., Landon, J., Sharman, S., Hakes, J., Suomi, A., \& Cowlishaw, S. (2018). Gambling and physical intimate partner violence: Results from the national epidemiologic survey on alcohol and related conditions (NESARC). American Journal on Addictions, 27(1), 7-14. https://doi.org/10.1111/ajad.12656.

Rothman, E. F., Johnson, R. M., \& Hemenway, D. (2006). Gun possession among Massachusetts batterer intervention program enrollees. Evaluation Review, 30(3), 283-295. https://doi.org/10.1177/ $0193841 X 06287221$

Schluter, P., Bellringer, M., \& Abbott, M. (2007). Maternal gambling associated with families' food, shelter, and safety needs: Findings from the Pacific Islands families study. Journal of Gambling Issues, (19), 87-90. https://doi.org/10.4309/jgi.2007.19.10.

Sherin, K. M., Sinacore, J. M., Li, X. Q., Zitter, R. E., \& Shakil, A. (1998). HITS: A short domestic violence screening tool for use in a family practice setting. Family Medicine-Kansas City, 30, 508512.

Spitzer, R. L., Kroenke, K., Williams, J. B., \& Löwe, B. (2006). A brief measure for assessing generalized anxiety disorder: The GAD-7. Archives of Internal Medicine, 166(10), 1092-1097. https://doi. org/10.1001/archinte.166.10.1092.
Straus, M. A. (2011). Gender symmetry and mutuality in perpetration of clinical-level partner violence: Empirical evidence and implications for prevention and treatment. Aggression and Violent Behavior, 16(4), 279-288. https://doi.org/10.1016/j.avb.2011.04.010.

Straus, M. A., \& Douglas, E. M. (2004). A short form of the revised conflict tactics scales, and typologies for severity and mutuality. Violence and Victims, 19(5), 507-520. https://doi.org/10.1891/vivi. 19.5.507.63686.

Suomi, A., Jackson, A. C., Dowling, N. A., Lavis, T., Patford, J., Thomas, S. A., Harvey, P., Abbott, M., Bellringer, M. E., Koziol-McLain, J., \& Cockman, S. (2013). Problem gambling and family violence: Family member reports of prevalence, family impacts and family coping. Asian Journal of Gambling Issues and Public Health, 3(13), 1-15. https://doi.org/10.1186/2195-3007-3-13.

Suomi, A., Dowling, N. A., Thomas, S., Abbott, M., Bellringer, M., Battersby, M., Koziol-McLain, J., \& Jackson, A. C. (2018). Patterns of family and intimate partner violence in problem gamblers. Journal of Gambling Studies, 1-20. https://doi.org/10.1007/ s10899-018-9768-9.

Tarzia, L., Forsdike, K., Feder, G., \& Hegarty, K. (2017). Interventions in health settings for male perpetrators or victims of intimate partner violence. Trauma, Violence \& Abuse, 1524838017744772, 152483801774477. https://doi.org/10.1177/1524838017744772.

Wardle, H., Moody, A., Spence, S., Orford, J., Volberg, R., Jotangia, D., Griffiths, M., Hussey, D., \& Dobbie, F. (2011). British Gambling Prevalence Survey 2010. Prepared for the gambling commission. London: National Centre for Social Research.

Williams, R. J., \& Volberg, R. A. (2014). The classification accuracy of four problem gambling assessment instruments in population research. International Gambling Studies, 14(1), 15-28. https://doi. org/10.1080/14459795.2013.839731.

Wood, R. T., \& Griffiths, M. D. (2007). A qualitative investigation of problem gambling as an escape-based coping strategy. Psychology and Psychotherapy: Theory, Research and Practice, 80(1), 107125. https://doi.org/10.1348/147608306x107881. 